\title{
Automated Epileptic Seizure Detection Model using WPT, CFS and KNN-based Multiclass TSVM
}

\author{
Sumant Kumar Mohapatra, Madhusmita Mohanty, Biswa Ranjan Swain
}

\begin{abstract}
The main aim of the proposed work is to generate an accurate automated seizure detection model for the performance evaluation of the improvement on epileptic patients in an improved manner. Long data sets of EEG signals are recorded for a long duration of time which has taken from PhysioNet CHB-MIT EEG datset for this experimental work. Six types of elements are excerpted from EEG signals by using WPT method and which is then classified by using CFS method. Then, all the features are combinely inputted to the rule based twin-support vector machines (TSVM $)_{s}$ to detect normal, ictal and pre-ictal EEG segments. The developed seizure detection WPT-KWMTSVM method achieved excellent performance with the average Accuracy, specificity, sensitivity, G-mean, positive predictive value, and Mathews correlation coefficients are 97.14\%, 97.33\%, 97.00\%, 97.31\%, 96.85\%, 95.96\% respectively The average area under curve (AUC) is approximately 1. The proposed method is able to enhance the seizure detection outcomes for proper clinical diagnosis in medical applications. Keywords: EEG Signal, Epileptic Seizure, WPT, CFS, Rule based TSVMs.
\end{abstract}

\section{INTRODUCTION}

Epilepsy is the leading neuronal abnormality of the brain, produced by concurrent disorder of a clutch of neurons which disturbs millions of human beings in the whole world [1]. The large data sets of EEG signals must be observed for a long duration of time for proper identification and analysis of epileptic seizures. For monitoring of Electroencephalogram signals of the patient's is very much monotonous and long delayed process. Along with that, the recorded EEG signal may get affected by various types of noise. Therefore, a real time monitoring and therapeutically automatic seizure detection method may be proposed. In [2] Rafiuddin et al. in the year 2011, developed an automated epileptic seizure detection method using 23 numbers of channels on 23 numbers of patients. In this research work, various statistical parameters are calculated from Electroencephalogram signals those are extracted from Wavelet coefficients. The experimented outcome in the form of Accuracy is $80.16 \%$.

Revised Manuscript Received on February 05, 2020.

* Correspondence Author

Sumant Kumar Mohapatra, Assistant Professor, Trident Academy of Technology, B.P.U.T, Bhubaneswar, Odisha, India.

Madhusmita Mohanty, B.E , electronics and Telecommunication engineering from the North Odisha University, India.

Biswa Ranjan Swain, Assistant Professor , Trident Academy of Technology, B.P.U.T, Bhubaneswar, Odisha

(C) The Authors. Published by Blue Eyes Intelligence Engineering and Sciences Publication (BEIESP). This is an open access article under the CC BY-NC-ND license (http://creativecommons.org/licenses/by-nc-nd/4.0/)
Khan et al. [3] designed an EEG seizure detector in the year 2012. In this research, $80 \%$ of EEG data are used for training. The relative values of energy are computed from wavelet coefficients. The proposed method [3] computed various statistical parameters as Specificity 100\%, Sensitivity $83.6 \%$, and accuracy $91.8 \%$ for five patients. Hunyadi et al [4] proposed an automated seizure detection technique using CHB-MIT EEG data sets. In this proposed method $80 \%$ of data was used for training for 23 numbers of patients. There are 16 numbers of elements are separated in various discrete domain. Sensitivity of $83 \%$ is calculated over the whole experimental works. In [5] authors analyzed the CHB-MIT EEG data sets using stacked auto encoders. In this experimental work, the method detected $100 \%$ of Sensitivity, considering 6 numbers of patients. In [6], authors implemented a seizure identification technique for extracting various discrete domain features, where $25 \%$ of data considered as the training data for 21 numbers of patients. It was experimented on 18 numbers of channels. The proposed method computed the various statistical parameters like Specificity of $94.71 \%$ and Sensitivity of $89.01 \%$.

Fiirbas et al. [7] proposed an automated seizure identification method where episcan is used. In this 23 numbers of patient's EEG data are utilized for experimental works. The Sensitivity of $67 \%$ is achieved. Samiee et al. [8] in 2015 extracted multivariate textural features from grey level co-occurrence matrix for epileptic Seizure detection. This method [8] used 23 patients, 23 channels and 25\% of data for training to complete the whole experimental works. The proposed method achieved $97.74 \%$ of Specificity and $70.19 \%$ of Sensitivity. In [9] Zabihi et al. proposed an epileptic seizure identification method where seven numbers of features were extracted using 23 numbers of patients and 23 numbers of channels. In this proposed work, 25\% and $50 \%$ of data are used for training purpose. The calculated results in form of avg. Specificity, Sensitivity and Accuracy rates are $93.21 \%$, $88.27 \%$ and $93.11 \%$ respectively for $25 \%$ training data and for $50 \%$ training data, the calculated results for avg. Specificity, Sensitivity and Accuracy rates are $94.80 \%$, 89.10\%, and 94.69\% respectively.

\section{A. CHB-MIT-EEG DATA SET}

In this work, long data sets of EEG signals are recorded for a long duration of time which has taken from PhysioNet [10] CHB-MIT Electroencephalogram dataset, mentioned in [11]. The Electroencephalogram signals are recorded from twenty-three numbers of affected people including both male and female. 
The age of affected male persons lies in the range of three to twenty-two years whereas the affected female persons are in the range of two to Nineteen years. The experimental analysis is done for individual patients, where minimum $\left(T_{\min }\right)$ and maximum $\left(T_{\max }\right)$ time period of seizure events are recorded. $T_{\min }$ and $T_{\max }$ are different for respective patient, similarly total seizure time and seizure free time are being recorded. The sampling rate for Electroencephalogram signals is $256 \mathrm{~Hz}$ and the recorded resolution is 16- bits. To record all the EEG signals twenty three EEG channels are utilized.

\section{METHODOLOGY}

\section{A. Wavelet Packet Decomposition}

All the three datasets (DS1, DS2, and DS3) containing scalp EEG data are demultiplexed at eighth level by WPT, which is the appropriate option for processing of EEG signals compared to Fast Fourier transform and Short-time Fourier transform [12, 13]. R.Dhiman et al, proposed a model to demultiplex signal using WPT [14]. The multi resolution analysis using WPD for a signal $\mathrm{g}(\mathrm{t})$ is specified $[15,16]$ :

$$
\begin{aligned}
& C_{0}^{0}=g(t) \\
& C_{i}^{q+1}=\sum_{k} h_{0}(k-2 t) C_{i}^{q} \\
& C_{2 i+1}^{q+1}=\sum_{k}^{k} h_{1}(k-2 t) C_{i}^{q} \\
& i=0,1,2, \ldots . .2^{q-1}
\end{aligned}
$$

Here, $C_{i}^{q}$ means the demultiplex coefficient at $i^{\text {th }}$ node of $q^{t h}$ level, $h_{0}(n)$ and $h_{1}(n)$ are orthogonal filters for demultiplexing method. $h_{1}(n)$ is transfer function of HPF and $h_{0}(n)$ is transfer function of LPF, which validates the following time domain equation :

$h_{1}(n)=(-1)^{n} h_{0}(n-1)$

\section{B. Feature Selection}

Correlation-based Feature Selection (CFS) method is implemented to filtrate out the subspace of elements that is mostly appropriate for the specified classification. The importance of Correlation-based Feature Selection algorithm is that it is very much useful and convenient for calculating the efficiency of a subspace of features as specified in Equation 5, which is applicable in the individual elements for the prediction of class.

$$
\text { Efficiency }_{T}=\frac{k r_{\overline{\mathrm{ef}}}}{\sqrt{k+k(k-1) r_{\overline{f f}}}}
$$

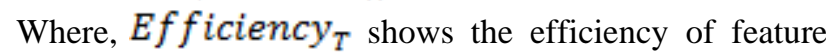
subset $\mathrm{T}$ containing $\mathrm{k}$ features, $r_{\bar{c} f}$ is the average feature class correlation and $r_{\bar{f} f}$ is the average feature-feature inter correlation. The correlation between the individual features must be computed properly to apply Equation no 5. In the first step, CFS discretizes numeric features using the technique of Fayyad and Irani [17] and then implemented symmetrical uncertainty (SU) for the estimation of degree of relevance between discrete features. Equation no 6 and 7 indicates the entropy of $\mathrm{Q}$.

$$
\begin{gathered}
H(Q)=\sum P_{Q}(x) \log _{2} \frac{1}{P_{Q}(x)} \\
H(Q / P)=-\sum_{p \in P} s(P) \sum_{q \in Q} s(q / p) \log _{2} s(q / p)
\end{gathered}
$$

Information gain is the amount of decrement of entropy for $\mathrm{Q}$ provided by $\mathrm{P}$ [18] that is specified in the following equations:

$$
\begin{aligned}
& \text { Gain }=H(Q)-H(Q / P)=H(P)-H(P / Q) \\
& =H(Q)+H(P)-H(P, Q)
\end{aligned}
$$

However, the information gain is more favorable towards the features having more values acquires more information than those of less values. Moreover the correlations specified in Eq. no 5 must be normalized to get the same effect for further comparison. Therefore, the SU [19] normalizes information gain's in the range of $[0,1]$ :

$$
S U=2.0 \times\left[\frac{\text { Gain }}{H(Q)+H(P)}\right]
$$

In the first step, CFS calculates feature-feature correlations and a matrix of feature-class from the training data and then searches for the feature subspace using various methods of searching methods. Here, a best fast search technique is used which initiates with a null set of features which produces every single feature expansions. The subspace with maximum evaluation is considered and the same steps repeated till the best subset is found.

\section{Rule Based Twin-Support Vector Machine}

In this research work, for classification of normal, interictal and ictal EEG signals, five number of rule based Twin SVMs are used. They are TSVM, Knn-TSVM [20], Knn-STSVM [21] and KWMTSVM [22] is used. There are many choices of dividing the recorded data into training and test [23] sets. In this study, cross validation is considered as $k=10$. For statistical parameter evaluation, $\mathrm{k}$-fold technique is used by using training and testing data sets. The average accuracy and other statistical parameters are experimentally computed after the process repeated for k-times.

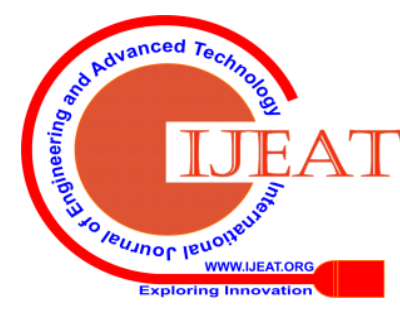




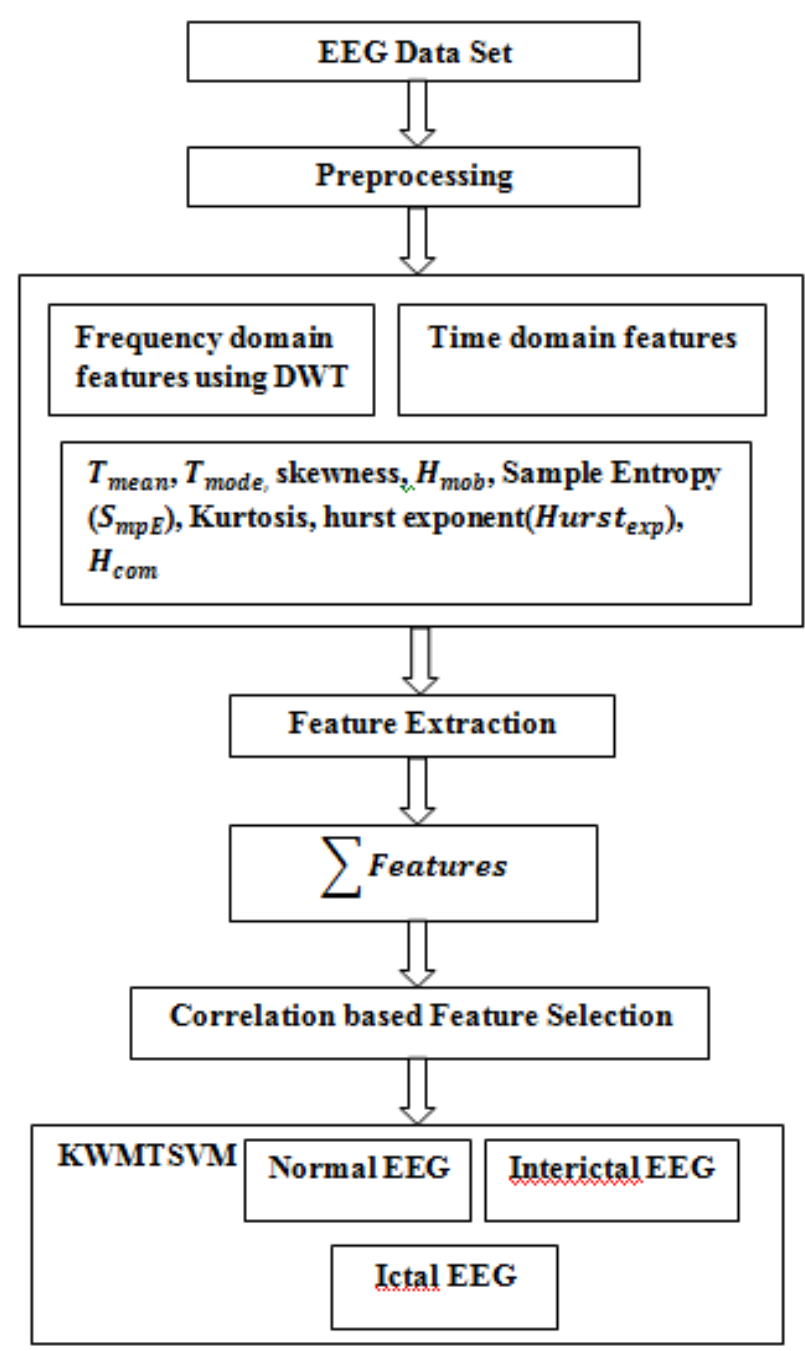

Fig.1. Block Diagram of the proposed method

\section{PERFORMANCE MATRIX:}

This research work evaluates the performance of the proposed methods using various statistical parameters [24] Accuracy (Ac), Specificity (Sp), Sensitivity (Se),G-mean(GM), Positive Predictive(PPV), Mathew's Correlation Coefficient(MCC), Area Under Curve(AUC) and also execution time are considered for the validation of the proposed method which are specified from Equation no (11) to Equation no (16).

$$
\begin{aligned}
& A_{c}=\frac{T P}{T P+T N+F P+F N} \\
& S_{p}=\frac{T N}{T N+F P} \\
& S_{B}=\frac{T P}{T P+F N} \\
& G_{M}=\sqrt{S_{e} \times S_{p}} \\
& P P V=\frac{T P}{T P+F P} \\
& M C C=\frac{(T P \times T N)-(F N \times F P)}{T 1 \times T 2} \\
& \text { Where, } \frac{T 1=\sqrt{(T P+F N)(T P+F P)}}{T 2}=\sqrt{(T N+F N)(T N+F P)}
\end{aligned}
$$

TP is True Positive, TN is True Negative

FP is False Positive, FN is False Negative

\section{RESULTS AND DISCUSSION:}

The block diagram of the proposed method is shown in "fig .1". Six numbers of Statistical parameters are calculated for the performance evaluation. In the proposed method, various classifiers are used like SVM, TSVM, KNN-TSVM, KNN-STSVM, and KWMTSVM for the evaluation of statistical parameters. It is experimented on 23 numbers of patients. Table-I shows that KWMTSVM classifier outperforms in all aspects of performance evaluation for every set of experimental works. Table-II shows the evaluated performance parameters using KWMTSVM classifier in which Accuracy, Specificity, Sensitivity, G-mean, PPV \& MCC are found out as $97.14 \%, 97.33 \%$, 97.00\%, 97.31\%, 96.85\%, 95.96\% respectively. The performance evaluation of the proposed method is also compared with the existing methods for the seizure detection

Table-I : Observation of Statistical parameters in proposed methods which is shown in Table-III.

\begin{tabular}{|l|r|r|r|r|l|}
\hline $\begin{array}{l}\text { Statistical } \\
\begin{array}{l}\text { Parameters } \\
(\%)\end{array}\end{array}$ & KWMTSVM & $\begin{array}{l}\text { KNN-STS } \\
\text { VM }\end{array}$ & $\begin{array}{l}\text { KNN-T } \\
\text { SVM }\end{array}$ & $\begin{array}{l}\text { TSV } \\
\text { M }\end{array}$ & $\begin{array}{l}\text { SV } \\
\text { M }\end{array}$ \\
\hline Accuracy & 97.14 & 95.18 & 91.48 & 88.69 & 75.8 \\
\hline Specificity & 97.33 & 95.25 & 92.06 & 87.54 & 74.9 \\
\hline Sensitivity & 97 & 94.26 & 90.65 & 83.4 & 80.5 \\
\hline G-mean & 97.31 & 93.39 & 91.3 & 85.75 & 78.8 \\
\hline PPV & 96.85 & 92.55 & 90.7 & 82.9 & 78.2 \\
\hline MCC & 95.96 & 90.85 & 85.95 & 81.67 & 77.5 \\
\hline
\end{tabular}

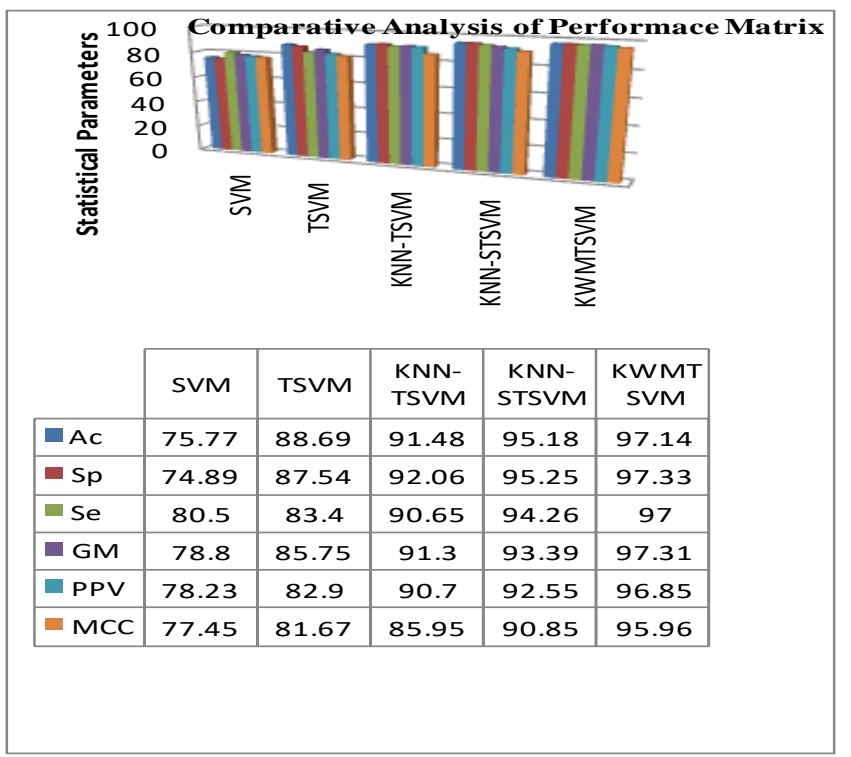

Fig.2. Comparative analysis of performance matrix using various classifiers 


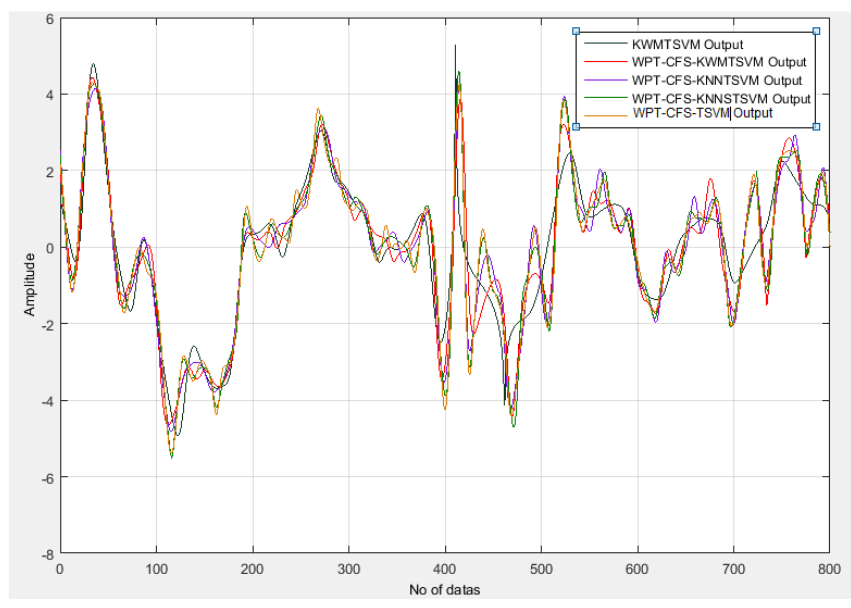

Fig. 3. Comparative outputs of the different classifiers

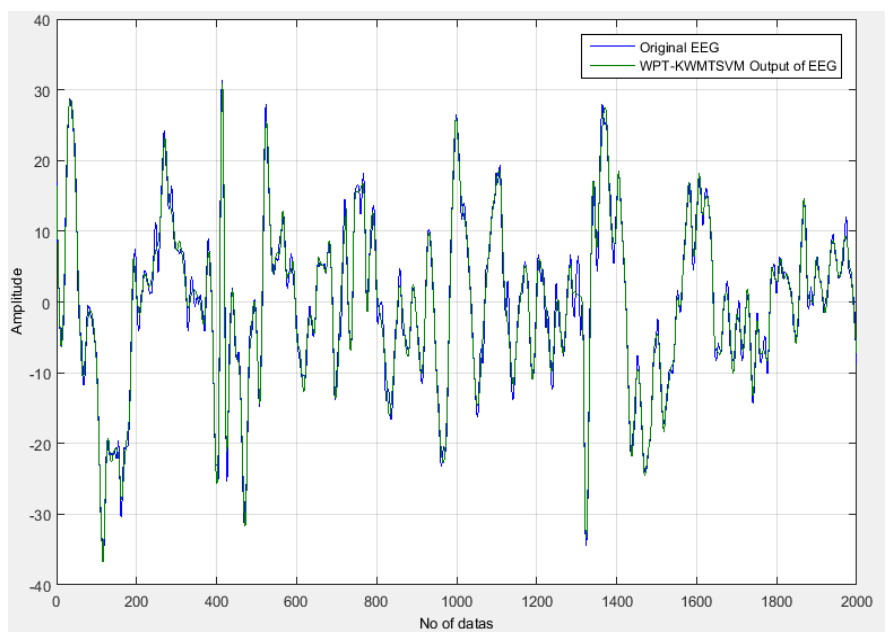

Fig. 4. Comparative output between original EEG Signal and WPT-CFS-KWMTSVM EEG signal

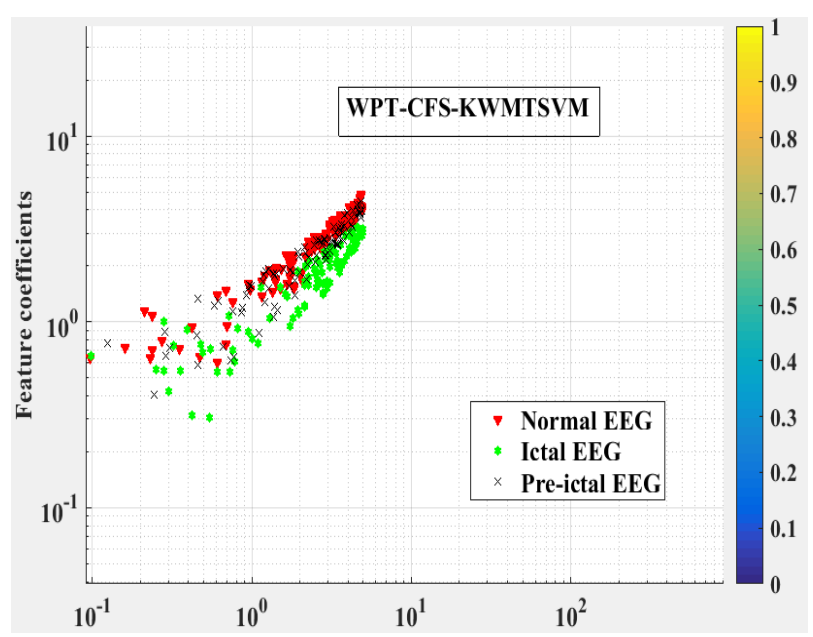

Fig. 5. Scatter plot of the proposed method differentiating Normal EEG, Ictal EEG and Pre-ictal EEG signals

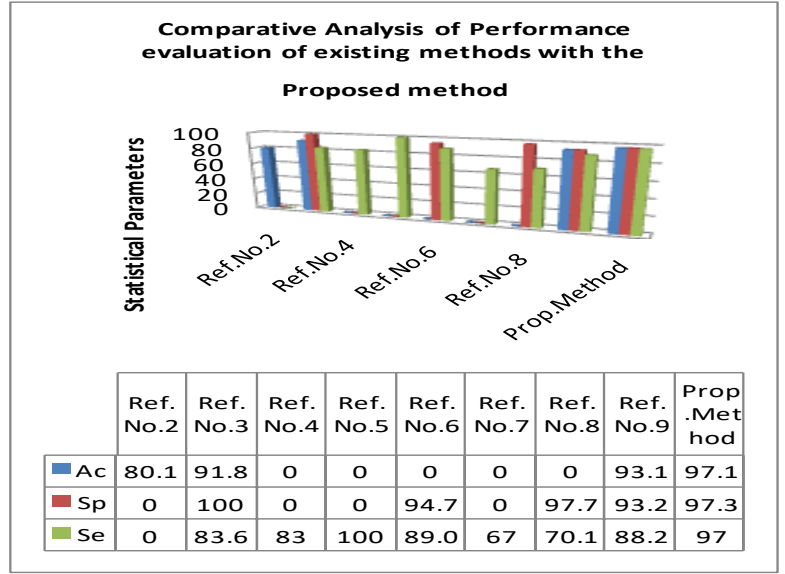

Fig. 6. Comparative analysis of performance evaluation of Existing methods with the proposed method 
Table-II : Evaluated performance parameters using KWMTSVM classifier

\begin{tabular}{|c|c|c|c|c|c|c|c|}
\hline \multirow{2}{*}{$\begin{array}{l}\text { METHOD } \\
\text { PATIENT INDEX }\end{array}$} & \multicolumn{7}{|l|}{ KWMTSVM CLASSIFIER } \\
\hline & FEATURE SETS & $A_{C}$ & $S_{P}$ & $S_{e}$ & $G_{M}$ & $P P V$ & MCC \\
\hline 1 & $T_{\text {mean }}, T_{\text {mode }}$ skewness, $H_{\text {mob }}$ & $93.9 \pm 1.12$ & $94.9 \pm 1.02$ & $95.8 \pm 1.17$ & $94.9 \pm 1.29$ & $97.6 \pm 1.42$ & $96.8 \pm 1.30$ \\
\hline 2 & $\begin{array}{l}\text { Sample Entropy }\left(S_{\text {mpE }}\right), T_{\text {mode }} \\
H_{\text {mob }}\end{array}$ & $96.7 \pm 1.14$ & $95.9 \pm 1.40$ & $94.9 \pm 1.30$ & $97.2 \pm 1.03$ & $95.5 \pm 1.51$ & $97.2 \pm 1.35$ \\
\hline 3 & $\begin{array}{l}\text { Kurtosis, hurst exponent(Hurst } \text { (Hxp }_{\text {exp }} \text {, } \\
H_{\text {com }}\end{array}$ & $96.9 \pm 1.27$ & $93.8 \pm 1.53$ & $96.2 \pm 1.12$ & $97.9 \pm 1.61$ & $90.9 \pm 1.50$ & $92.8 \pm 1.72$ \\
\hline 4 & $T_{\text {mean }}, T_{\text {mode }} H_{\text {com }}$ & $97.9 \pm 1.02$ & $98.7 \pm 1.60$ & $96.0 \pm 1.62$ & $97.8 \pm 1.51$ & $93.1 \pm 1.01$ & $94.3 \pm 1.08$ \\
\hline 5 & $\begin{array}{l}\text { skewness, hurst exponent } \\
\left.\text { (Hurst }{ }_{\operatorname{sxp}}\right), \text { kurtosis }\end{array}$ & $98.7 \pm 1.57$ & $97.2 \pm 1.70$ & $97.7 \pm 1.50$ & $99.0 \pm 1.64$ & $94.4 \pm 1.32$ & $95.7 \pm 1.02$ \\
\hline 6 & $T_{\text {mean, skewness, }} H_{\text {mob }}$ & $99.6 \pm 1.63$ & $99.4 \pm 1.22$ & $97.4 \pm 1.20$ & $95.8 \pm 1.73$ & $96.9 \pm 1.75$ & $95.7 \pm 1.35$ \\
\hline 7 & 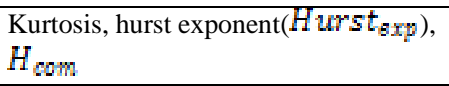 & $98.7 \pm 1.87$ & $96.2 \pm 1.30$ & $98.2 \pm 1.45$ & $98.7 \pm 1.69$ & $98.9 \pm 1.82$ & $94.0 \pm 1.26$ \\
\hline 8 & $T_{\text {modeg }}$ skewness, $H_{\text {mob }}$ & $94.9 \pm 1.32$ & $97.5 \pm 1.20$ & $93.9 \pm 1.75$ & $98.1 \pm 1.20$ & $98.5 \pm 1.63$ & $94.5 \pm 1.51$ \\
\hline 9 & $\begin{array}{l}T_{\text {mean, }} \text { Sample Entropy }\left(S_{\text {mpE }}\right) \text {, } \\
T_{\text {mode }} H_{\text {com }}\end{array}$ & $93.7 \pm 1.65$ & $98.0 \pm 1.45$ & $99.9 \pm 1.50$ & $92.9 \pm 1.67$ & $99.2 \pm 1.50$ & $96.8 \pm 1.40$ \\
\hline 10 & $T_{\text {maan }} T_{\text {model }}$ skewness, $H_{\text {mob }}$ & $95.8 \pm 1.73$ & $96.9 \pm 1.75$ & $95.7 \pm 1.35$ & $99.7 \pm 1.49$ & $98.0 \pm 1.55$ & $95.8 \pm 1.37$ \\
\hline 11 & $T_{\text {mean }} T_{\text {mode }} H_{\text {com }}$ & $99.7 \pm 1.69$ & $98.9 \pm 1.82$ & $94.0 \pm 1.26$ & $98.8 \pm 1.70$ & $97.9 \pm 1.25$ & $98.6 \pm 1.59$ \\
\hline 12 & $\begin{array}{l}\text { Sample Entropy }\left(S_{\operatorname{mpE}}\right), T_{\text {mode }} \\
H_{\text {com }}\end{array}$ & $98.9 \pm 1.20$ & $98.5 \pm 1.63$ & $93.5 \pm 1.51$ & $93.7 \pm 1.05$ & $97.0 \pm 1.92$ & $96.8 \pm 1.55$ \\
\hline 13 & $\begin{array}{l}T_{\text {mean, }} \text { Kurtosis, hurst } \\
\left.\text { exponent(Hurst } t_{\text {gxp }}\right), H_{\text {com }}\end{array}$ & $97.8 \pm 1.50$ & $99.3 \pm 1.35$ & $98.8 \pm 1.48$ & $94.5 \pm 1.64$ & $98.5 \pm 1.09$ & $95.9 \pm 1.75$ \\
\hline 14 & 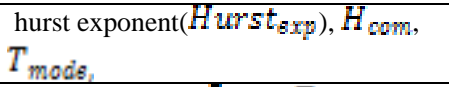 & $91.9 \pm 1.35$ & $99.9 \pm 1.52$ & $99.5 \pm 1.38$ & $98.9 \pm 1.55$ & $92.9 \pm 1.02$ & $95.9 \pm 1.65$ \\
\hline 15 & $\begin{array}{l}\text { Sample Entropy }\left(S_{\text {mpE }}\right), T_{\text {mode }} \\
H_{\text {mob }}\end{array}$ & $98.0 \pm 1.72$ & $95.7 \pm 1.80$ & $98.9 \pm 1.47$ & $98.7 \pm 1.90$ & $93.0 \pm 1.43$ & $97.5 \pm 1.50$ \\
\hline 16 & $\begin{array}{l}\left.T_{\text {mean }} \text {, hurst exponent(Hurst } t_{\text {gxp }}\right) \text {, } \\
H_{\text {com }}\end{array}$ & $96.5 \pm 1.45$ & $97.8 \pm 1.12$ & $97.9 \pm 1.82$ & $96.7 \pm 1.24$ & $96.9 \pm 1.40$ & $94.9 \pm 1.30$ \\
\hline 17 & $T_{\text {mods }}$, skewness, $H_{\text {mob }}$ & $92.9 \pm 1.67$ & $99.2 \pm 1.50$ & $96.8 \pm 1.40$ & $96.9 \pm 1.27$ & $96.8 \pm 1.53$ & $97.3 \pm 1.37$ \\
\hline 18 & $\begin{array}{l}\text { Sample Entropy }\left(S_{\operatorname{mpE}}\right), T_{\text {mode }} \\
H_{\text {com }}\end{array}$ & $99.7 \pm 1.49$ & $98.1 \pm 1.55$ & $95.8 \pm 1.37$ & $97.5 \pm 1.45$ & $98.4 \pm 1.65$ & $96.1 \pm 1.67$ \\
\hline 19 & $T_{\text {masn, skewness, }} H_{\text {mob }}$ & $98.9 \pm 1.92$ & $97.9 \pm 1.25$ & $98.6 \pm 1.59$ & $98.9 \pm 1.29$ & $99.5 \pm 1.60$ & $95.5 \pm 1.55$ \\
\hline 20 & $\begin{array}{l}\text { hurst exponent(Hurst } \text { Hexp }_{\text {en }} \text {, } \\
\text { skewness, } H_{\text {com }}\end{array}$ & $97.9 \pm 1.65$ & $93.9 \pm 1.12$ & $95.9 \pm 1.65$ & $97.8 \pm 1.65$ & $99.4 \pm 1.39$ & $98.1 \pm 1.40$ \\
\hline 21 & $\begin{array}{l}\text { Sample Entropy }\left(S_{\operatorname{mpE}}\right), T_{\text {mode }} \\
H_{\text {mob }}\end{array}$ & $98.7 \pm 1.90$ & $93.0 \pm 1.43$ & $97.5 \pm 1.50$ & $97.9 \pm 1.24$ & $98.0 \pm 1.66$ & $93.1 \pm 1.04$ \\
\hline 22 & $T_{\text {mean, skewness, }} H_{\text {mob }}$ & $98.0 \pm 1.55$ & $98.9 \pm 1.75$ & $99.7 \pm 1.25$ & $99.1 \pm 1.74$ & $98.9 \pm 1.19$ & $99.0 \pm 1.35$ \\
\hline 23 & $\begin{array}{l}\text { Sample Entropy }\left(S_{\operatorname{mpE}}\right), \text { hurst } \\
\left.\text { exponent( } H u r s t_{\operatorname{sxp}}\right), H_{c o m}\end{array}$ & $98.7 \pm 1.70$ & $99.0 \pm 1.65$ & $98.5 \pm 1.07$ & $96.9 \pm 1.08$ & $97.5 \pm 1.48$ & $94.9 \pm 1.05$ \\
\hline Average & $\begin{array}{l}\text { Six numbers of features are extracted } \\
\text { using WPT, CFS, KWMTSVM }\end{array}$ & 97.14 & 97.33 & 97.00 & 97.31 & 96.85 & 95.96 \\
\hline
\end{tabular}

Published By: 
Table-III Comparative Analysis of existing methods and the proposed method

\begin{tabular}{|c|c|c|c|c|c|c|c|c|}
\hline Reference No. & Year & Method & $\begin{array}{l}\text { Ac } \\
\text { (\%) }\end{array}$ & $\begin{array}{l}\text { Sp } \\
\text { (\%) }\end{array}$ & $\begin{array}{l}\text { Se } \\
(\%)\end{array}$ & $\begin{array}{l}\text { GM } \\
(\%)\end{array}$ & $\begin{array}{l}\text { PVV } \\
\text { (\%) }\end{array}$ & $\begin{array}{l}\text { MCC } \\
(\%)\end{array}$ \\
\hline 2 & 2011 & $\begin{array}{l}\text { Statistical parameters } \\
\text { calculated from EEG signal } \\
\text { considering the wavelet } \\
\text { coefficients }\end{array}$ & 80.16 & $\begin{array}{l}\text { Not } \\
\text { recorded }\end{array}$ & $\begin{array}{l}\text { Not } \\
\text { recorded }\end{array}$ & $\begin{array}{l}\text { Not } \\
\text { recorded }\end{array}$ & $\begin{array}{l}\text { Not } \\
\text { recorded }\end{array}$ & $\begin{array}{l}\text { Not } \\
\text { recorded }\end{array}$ \\
\hline 3 & 2012 & $\begin{array}{l}\text { Relative values of energy \& } \\
\text { normalized coefficients of } \\
\text { variations calculated from } \\
\text { Wavelet coefficients }\end{array}$ & 91.8 & 100 & 83.6 & $\begin{array}{l}\text { Not } \\
\text { recorded }\end{array}$ & $\begin{array}{l}\text { Not } \\
\text { recorded }\end{array}$ & $\begin{array}{l}\text { Not } \\
\text { recorded }\end{array}$ \\
\hline 4 & 2012 & $\begin{array}{l}\text { Sixteen numbers of features, } \\
\text { extracted in time and frequency } \\
\text { domain }\end{array}$ & $\begin{array}{l}\text { Not } \\
\text { recorded }\end{array}$ & $\begin{array}{l}\text { Not } \\
\text { recorded }\end{array}$ & 83 & $\begin{array}{l}\text { Not } \\
\text { recorded }\end{array}$ & $\begin{array}{l}\text { Not } \\
\text { recorded }\end{array}$ & $\begin{array}{l}\text { Not } \\
\text { recorded }\end{array}$ \\
\hline 5 & 2014 & $\begin{array}{l}\text { Unsupervised feature learning } \\
\text { using Stacked auto encoders }\end{array}$ & $\begin{array}{l}\text { Not } \\
\text { recorded }\end{array}$ & $\begin{array}{l}\text { Not } \\
\text { recorded }\end{array}$ & 100 & $\begin{array}{l}\text { Not } \\
\text { recorded }\end{array}$ & $\begin{array}{l}\text { Not } \\
\text { recorded }\end{array}$ & $\begin{array}{l}\text { Not } \\
\text { recorded }\end{array}$ \\
\hline 6 & 2014 & $\begin{array}{l}\text { Features were extracted in time } \\
\text { and frequency domain }\end{array}$ & $\begin{array}{l}\text { Not } \\
\text { recorded }\end{array}$ & 94.71 & 89.01 & $\begin{array}{l}\text { Not } \\
\text { recorded }\end{array}$ & $\begin{array}{l}\text { Not } \\
\text { recorded }\end{array}$ & $\begin{array}{l}\text { Not } \\
\text { recorded }\end{array}$ \\
\hline 7 & 2015 & $\begin{array}{l}\text { Automatic method for Seizure } \\
\text { detection using Episcan }\end{array}$ & $\begin{array}{l}\text { Not } \\
\text { recorded }\end{array}$ & $\begin{array}{l}\text { Not } \\
\text { recorded }\end{array}$ & 67 & $\begin{array}{l}\text { Not } \\
\text { recorded }\end{array}$ & $\begin{array}{l}\text { Not } \\
\text { recorded }\end{array}$ & $\begin{array}{l}\text { Not } \\
\text { recorded }\end{array}$ \\
\hline 8 & 2015 & $\begin{array}{l}\text { Multivariate textural features } \\
\text { were extracted from grey level } \\
\text { co-occurrence matrix for } \\
\text { epileptic Seizure detection }\end{array}$ & $\begin{array}{l}\text { Not } \\
\text { recorded }\end{array}$ & 97.74 & 70.19 & $\begin{array}{l}\text { Not } \\
\text { recorded }\end{array}$ & $\begin{array}{l}\text { Not } \\
\text { recorded }\end{array}$ & $\begin{array}{l}\text { Not } \\
\text { recorded }\end{array}$ \\
\hline 9 & 2016 & $\begin{array}{l}\text { An epileptic seizure detection } \\
\text { method in which seven numbers } \\
\text { of features were extracted ( } \\
\text { considering 25\% training data) }\end{array}$ & 93.11 & 93.21 & 88.27 & $\begin{array}{l}\text { Not } \\
\text { recorded }\end{array}$ & $\begin{array}{l}\text { Not } \\
\text { recorded }\end{array}$ & $\begin{array}{l}\text { Not } \\
\text { recorded }\end{array}$ \\
\hline 9 & 2016 & $\begin{array}{l}\text { An epileptic seizure detection } \\
\text { method in which seven numbers } \\
\text { of features were extracted ( } \\
\text { considering } 50 \% \text { training data) }\end{array}$ & 94.69 & 94.80 & 89.10 & $\begin{array}{l}\text { Not } \\
\text { recorded }\end{array}$ & $\begin{array}{l}\text { Not } \\
\text { recorded }\end{array}$ & $\begin{array}{l}\text { Not } \\
\text { recorded }\end{array}$ \\
\hline $\begin{array}{l}\text { Proposed } \\
\text { method }\end{array}$ & 2019 & $\begin{array}{l}\text { Six numbers of features are } \\
\text { extracted using WPT, CFS, } \\
\text { KWMTSVM }\end{array}$ & 97.14 & 97.33 & 97.00 & 97.31 & 96.85 & 95.96 \\
\hline
\end{tabular}

\section{CONCLUSION}

In this research work, an unprecedented Seizure detection algorithm has been proposed for the analysis of multivariate non-stationary EEG signals. All the three datasets (DS1, DS2, and DS3) containing scalp EEG data are first of all decomposed by Wavelet Packet Transform (WPT). Then, Correlation-based Feature Selection method is used for the selection of the features. Finally, all the features are inputted to different rule based Support Vector Machines like SVM,

TSVM, KNN-TSVM, KNN-STSVM, and KWMTSVM for the evaluation of statistical parameters. In this experimented work, it is observed that, KWMTSVM outperforms in every aspects compared to other classifiers. The outcomes in terms of Accuracy, Specificity, Sensitivity, G-mean, PPV \& MCC are found out as 97.14\%, 97.33\%, 97.00\%, 97.31\%, 96.85\%, $95.96 \%$ respectively for KWMTSVM. The proposed method will be experimented on short data of EEG signal in future.

\section{REFERENCES:}

1. H.Witte et al, "Special issue on epileptic seizure prediction", IEEE Transactions on Biomedical Engineering, vol. 50, no. 5, pp. 537-539, May 2003.

2. N. Rafiuddin et al, "Feature extraction and classification of EEG for automatic Seizure detection", International Conference on Multimedia, Signal Processing and Communication Technologies, 2011, pp. 184-187.

3. Y. U. Khan et al, "Automated seizure detection in scalp EEG using multiple wavelet scales", IEEE International Conference on Signal Processing, Computing and Control, March 2012, pp 1-5.
4. B. Hunyadi et al, "Incorporating structural information from the multichannel EEG improves patient-specific seizure detection", Clinical Neurophysiology, vol.123, no. 12, pp. 2352-2361, 2012.

5. A. Supratak et al, "Feature extraction with stacked autoencoders for epileptic seizure detection", $36^{\text {th }}$ Annual International Conference of the IEEE Engineering in Medicine and Biology Society, 2014, pp. 4184-4187.

6. S. Kiranyaz et al, "Automated patient-specific classification of long term electroencephalography", Journal of Biomedical Informatics, vol.49, pp. 16-31, 2014.

7. F.Fiirbas et al, "Prospective multi-center study of an automatic online seizure detection system for epilepsy monitoring units", Clinical neurophysiology, vol. 126, no. 6, pp. 1124-1131, 2015.

8. K. Samiee et al, "Long-term epileptic EEG classification via 2D mapping and textural features", Expert Systems with Applications, vol. 42, no. 20, pp. 7175-7185, 2015.

9. M. Zabihi et al, "Analysis of high-dimensional phase space via Poincare section for patient-specific seizure detection", IEEE Transactions on Neural Systems and Rehabilitation engineering, vol. 24, no. 3, pp. 386-398, 2016.

10. A. L. Goldberger et al., "Physiobank, physiotoolkit, and physonet components of a new research resource for complex physiologic signals", Circulation, vol. 101, no. 23, pp. e215-e220, 2000.

11. A. H. Shoeb, "Application of machine learning to epileptic seizure onset detection and treatment", Ph.D. dissertation, Massachusetts Institute of Technology, 2009.

12. J. A. Chambers et al, "EEG Signal Processing", Wiley, New York, 2007.

13. T. Gandhi et al, "Expert model for detection of epileptic activity in EEG signature", Expert System, Appl. 37 (2010) 3513-3520.

14. R. Dhiman et al, "Genetic Algorithms tuned expert model for detection of epileptic seizures from EEG signatures”, Appl. Soft Computing, J. 19 (2014) 8-17.

15. X.Jiao et al, "An algorithm for improving the co-efficient accuracy of Wavelet packet analysis, Meas. J. International Meas. Confed. 47 (2014) 207-220.

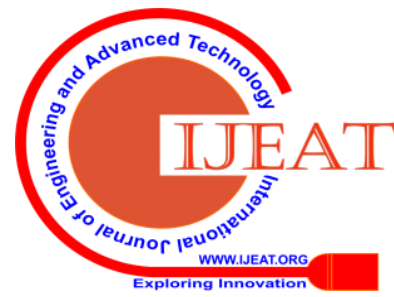


16. S. Mallat, " A wavelet Tour of Signal Processing”, Academic Press, New York, 1999.

17. K. B. Irani, "Multi-interval discretization of continuous-valued attributes for classification learning", 1993.

18. J. Quinlan, “ C4.5:Program for machine learning morgan Kaufmann",San Mateo, CA, USA, 1993.

19. W. Press and B. Flannery, "Sa teukolsky, wt vetterling (1998), numerical recipes in C", Cambridge [ua].

20. Q. Ye, C. Zhao, S. Gao, H. Zheng, Weighted twin support vector machines with local information and its application, Neural Networks, Vol. 35, p31-39, 2012.

21. X. Pan, Y. Luo, Y. Xu, K-nearest neighbor based structural twin support vector machine, Knowledge-based Systems, Vol. 88, p34-44, 2015.

22. Yitian $\mathrm{Xu}, \mathrm{K}$-nearest neighbor-based weighted multi-class twin support vector machine, Neurocomputing, http://dx.doi.org/10.1016/j.neucom.2016.04.024.

23. W. A. Chaovalitwongse, Y. J. Fan, and R. C. Sachdeo, "On the time series k-nearest neighbor classification of abnormal brain activity”,Systems, Man and Cybernetics, Part A: Systems and Humans, IEEETransactions on, vol. 37, no. 6, pp. 1005-1016,2007.

24. A.T. Azhar and S.A. El-Said, "Performance analysis of Support vector machine classifiers in breast cancer mammography recognition", Neural Computing and Applications, Vol-24, no-5, pp. 1163-1177, 2014.

\section{AUTHORS PROFILE}

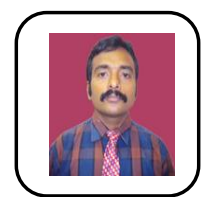

Sumant Ku Mohapatra was born in Bhubaneswar, Orissa, India. He received the B.Tech degree from ITER, Bhubaneswar, India in 2002 \& M.Tech(Electronics \& Instrumentation Engg) from GIET, BPUT, Odisha in 2011. Currently he is working in Trident Academy of Technology, B.P.U.T, Bhubaneswar, Odisha, India as an Assistant Professor. His research interest are in signal and image processing Biomedical Signal Processing ,optical fiber communication and wireless communication. He is a member of IETE , member of ISTE.

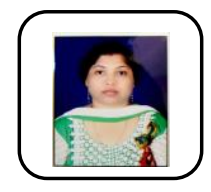

Madhusmita Mohanty received the B.E in electronics and Telecommunication engineering from the North Odisha University in 2001 and ME degrees in communication engineering from Jadavpur University in 2007. She is presently Ph.D. candidate in Jadavpur University in signal processing. Her research interests include the biomedical signal processing and advancement in brain analysis. She is a Member of IETE.

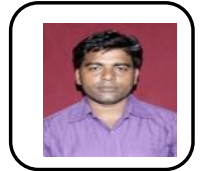

Biswa Ranjan Swain was born in the Cuttack district, Odisha, India . He received the B.Tech degree from SIET, Dhenkanal, India in 2006 \& M.Tech(Electronics \& Telecommunication Engg.) from IIT Kharagpur, Kharagpur, India. Currently he is working in Trident Academy of Technology, B.P.U.T, Bhubaneswar, Odisha, as an Assistant Professor. His research interest are in signal processing , and wireless communication, Biomedical Signal Processing and Design of Antenna. He is a member of IETE , member of ISTE. 